\title{
O processo de (des)proletarização do professor da educação básica
}

\author{
Ruth Pavani \& José Licínio Backesii \\ Universidade Católica Dom Bosco, Brasil
}

Resumo

A proletarização caracteriza-se pela dificuldade ou impossibilidade de o professor refletir sobre sua prática docente. Caracteriza-se, ainda, pela perda de sua qualificação (para planejar, analisar, atuar e avaliar) e do controle sobre seu processo de trabalho, o que o torna refém do controle externo, diminuindo progressivamente sua capacidade de autonomia e resistência. $\mathrm{O}$ objetivo deste artigo consiste em refletir sobre a proletarização do professor da educação básica no contexto atual, como se dá esse processo e as possibilidades de rompê-lo. A pesquisa de campo foi realizada por meio de entrevistas com professores do Ensino Fundamental e Médio de escolas localizadas na região centro-oeste do Brasil. Pela pesquisa efetuada, concluímos que os professores entrevistados estão submetidos ao processo de proletarização, embora este não seja total e absoluto, pois foi possível identificar microespaços de resistência.

Palavras-chave

Formação de professores; Proletarização; Reflexão crítica

\section{Introdução}

Nos últimos anos, no contexto brasileiro, tem se observado uma intensificação das políticas de controle em todos os níveis de educação, sobretudo pela adoção de uma política de verificação de resultados a partir da adoção de exames nacionais padronizados. Os resultados dessas 
verificações, além de servirem para supostamente indicar os níveis de qualidade da educação, são utilizados como forma de acesso à Educação Superior e distribuição de bolsas, entre outros. Eles têm servido também para estabelecer rankings entre as diferentes instituições, sugerindo a excelência de algumas e a deficiência da maioria. Na educação básica, esses exames têm sido utilizados pela retórica conservadora para evidenciar a fragilidade da escola pública e a excelência da escola privada. Como consequência dessa constatação, a escola privada passa a ser considerada como um modelo de sucesso a ser seguido pela escola pública, que é vista como modelo de fracasso.

Outro efeito dessas políticas tem a ver diretamente com a discussão deste artigo, isto é, com a intensificação do processo de proletarização dos professores da educação básica. Eles são pressionados a seguirem os conteúdos cobrados pelos exames, e o bom desempenho dos alunos passa a ser visto como a finalidade da educação. Assim, pensar ou refletir criticamente sobre quais conteúdos selecionar ou o que se deseja de um processo educativo, além de não ser uma tarefa necessária para o professor, já que isso está definido a priori, é visto como perda de tempo, sendo a preocupação maior trabalhar os conteúdos que serão cobrados nos exames externos.

A análise crítica desse processo indica que os resultados dessas avaliações, mais do que serem utilizados como um diagnóstico para repensar o processo educativo ou um indicativo para futuros investimentos, são usados para classificar, selecionar, estabelecer rankings, reforçando cada vez mais a ideia de que o mérito é o critério a ser seguido e retirando a autonomia do professor, que se proletariza cada vez mais. A análise crítica nos faz apostar em diferentes formas de transgredir e subverter esse processo de proletarização.

Nesse contexto de reflexão crítica, insere-se este artigo, fruto de pesquisa docente financiada pelo CNPq (Edital Humanas e Sociais Aplicadas/2011). O objetivo consiste em refletir sobre a proletarização do professor da educação básica no contexto atual, como se dá esse processo e as possibilidades de romper com ele. O texto foi desenvolvido no âmbito das reflexões do grupo de pesquisa "Currículo, práticas pedagógicas e formação de professores", cadastrado no CNPq. 
Para recolher os dados da pesquisa de campo, foram realizadas entrevistas com professores do Ensino Fundamental e Médio das redes pública e privada de escolas localizadas na região centro-oeste do Brasil. A fim de manter o anonimato dos sujeitos da pesquisa, os nomes dos professores são fictícios.

Para atender ao objetivo proposto, o texto foi organizado da seguinte forma: em primeiro lugar, situamos a pesquisa no contexto brasileiro; depois escrevemos sobre o processo de proletarização, enfatizando seu significado e como o contexto atual dificulta a reflexão do professor sobre sua prática docente, entendida como uma prática eminentemente política, tal como afirma Giroux (2003). Em seguida, apresentamos a análise das entrevistas realizadas, articulando-as com o processo de proletarização, e apontamos a formação crítica como meio de fomentar as possibilidades de romper com o processo de proletarização.

\section{Situando a pesquisa no contexto brasileiro}

Muitos são os autores no Brasil que têm se dedicado a investigar criticamente as atuais políticas de educação e como estas têm afetado os currículos e o trabalho dos professores (Alves, 2009; Gandin \& Lima, 2015; Grischke \& Hypólito, 2009; Hypólito, 2010; Oliveira, 2004, 2007, 2013; Santos, 2013; Santos, Guimarães-losif, \& Chaves, 2013). Embora essas políticas afetem também a Educação Superior, neste artigo privilegiaremos a Educação Básica. Esses autores destacam que:

a) O contexto educacional brasileiro, desde os anos 1990, tem sofrido as influências da reforma do Estado, alinhadas às políticas neoliberais e gestadas por um conjunto de organismos internacionais, com destaque para o Banco Mundial, o Banco Interamericano de Desenvolvimento (BID), o Fundo Monetário Internacional (FMI), a Organização das Nações Unidas para a Educação, a Ciência e a Cultura (UNESCO), a Organização para Cooperação e Desenvolvimento Econômico (OCDE) e a Organização dos Estados Ibero-americanos para a Ciência e a Cultura (OEI). Essas políticas educacionais partem do pressuposto de que o Estado é ineficiente e de que a iniciativa privada é 
eficiente; portanto, para que a educação seja bem-sucedida, ela deve seguir a lógica empresarial. No contexto brasileiro, mesmo após a eleição de um Presidente da República alinhado aos movimentos sociais, não houve mudança significativa; pelo contrário, houve uma intensificação das políticas de mercantilização da educação.

b) Com essas políticas educacionais, muda significativamente o papel que o Estado exerce na educação, bem como a própria finalidade da educação. O Estado é visto mais como um fiscal e controlador da educação do que alguém que oferece a educação. Ou a oferta é da iniciativa privada, ou, no mínimo, deseja-se que seja em parceria com a iniciativa privada: "o Estado passa apenas a gerir a política pública estabelecida, não sendo mais o provedor" (Gandin \& Lima, 2015, p. 666). Mesmo com escolas que continuam públicas, a lógica é profundamente alterada, pois é regida pelos critérios de produtividade, excelência, eficácia, eficiência, competitividade e competência, portanto, alinhada com o mercado capitalista. A finalidade da educação passa a ser formar crianças e jovens segundo as demandas do mercado. As transformações visam a um "determinado modo de ser, centrado na ideia de consumo e de autonomia do sujeito, como um consumidor, apto para escolher autonomamente" (Hypólito, 2010, p. 1340).

c) Essas políticas mudam também profundamente a vida dos professores, suas formas de valorização, suas carreiras, sua remuneração. No contexto brasileiro, a democratização do acesso ao ensino veio acompanhada pela crescente desvalorização docente (Oliveira, 2004, 2007, 2013). Seguindo os princípios do neoliberalismo, com a flexibilização das leis trabalhistas e a produtividade como parâmetro de remuneração, intensifica-se a precarização das relações de trabalho (contratos temporários, professores substitutos) mesmo nas instituições públicas. Os sindicatos, antes tidos como centrais para a defesa dos professores, são criticados pelos agentes do mercado, sendo vistos como corporativistas e avessos às inovações, ficando fragilizados. Cada vez é mais comum que Estados e municípios 
atrelem a remuneração dos professores ao seu desempenho, leiase, às notas obtidas pelos alunos em avaliações externas. Esse sistema de remuneração incentiva a competição entre os professores e enfraquece o trabalho coletivo: "a tendência é de que ocorra uma competição desenfreada pelo bom desempenho, como se fora uma competição para quem ganha mais no mercado" (Hypólito, 2010, p. 1348). Mesmo com a criação do piso salarial profissional nacional para os profissionais do magistério público da educação básica em 2008, o quadro não se alterou significativamente: além de o valor ser muito baixo, muitos Estados e municípios não cumprem a lei.

d) As políticas neoliberais produzem uma forte responsabilização dos professores pelo fracasso dos alunos, entendido como mau desempenho nas avaliações externas. As mudanças provocadas no trabalho pedagógico, resultado da gestão mercadológica e da nova organização do trabalho, produzem uma maior responsabilização dos professores (Oliveira, 2004, 2007, 2013). insucesso da educação pública no Brasil "recai em última instância na responsabilização das escolas, do corpo docente, dos estudantes, dos pais" (Hypólito, 2010, p. 1343). Em caso de parcerias com a iniciativa privada, a responsabilidade pelo fracasso é atribuída aos professores, nunca à iniciativa privada (Grischke \& Hypólito, 2009). Esse processo de responsabilização, produzido num primeiro momento fora do ambiente escolar (sobretudo do mundo empresarial), é incorporado por muitos professores, que se assumem como responsáveis, como se a educação fosse reduzida à sala de aula, desconsiderando-se os inúmeros elementos externos que a condicionam (Oliveira, 2013). Isso produz um forte sentimento de ineficiência, e, nos lugares em que as políticas atrelam a remuneração ao desempenho, a culpa pelo salário aviltante recebido é vista como sendo do próprio professor.

e) As políticas neoliberais intensificaram o trabalho docente. No contexto brasileiro, há décadas o professor da escola básica, muitas vezes, se vê obrigado a trabalhar três turnos e em várias escolas, dadas as condições salariais. Com a lógica empresarial no 
campo da educação, novas demandas são exigidas dos professores; sobretudo, há uma intensificação do trabalho burocrático do professor para que seu trabalho possa ser mensurado: "(...) quando a mensuração da ação docente é mais importante que o conteúdo dessa ação, o trabalho docente limitase, é intensificado e requalificado de forma a ser reduzido a um trabalho encenado, destinado ao monitoramento" (Gandin \& Lima, 2015, p. 676). De certo modo, há também uma autointensificação do trabalho docente (Grischke \& Hypólito, 2009; Oliveira, 2007; Santos et al., 2013), já que os professores, por serem responsabilizados pelo desempenho dos seus alunos, se autovigiam e sempre estão em busca de fazer mais e melhor para que seus alunos aprendam, abrindo mão do seu já escasso tempo livre.

f) As políticas neoliberais, além de produzirem novas políticas de currículo, interferem diretamente na forma como o currículo é desenvolvido em sala de aula pelos professores. Cabe destacar que os autores em quem nos baseamos incorporam as discussões contemporâneas de currículo, que o veem não só como um documento legal, mas como tudo que ocorre no âmbito escolar, incluindo o trabalho pedagógico. Concebemos "currículo como todas as experiências organizadas pela escola que se desdobram em torno do conhecimento escolar" (Moreira, 2001, p. 68). Nesse sentido, fazem parte do currículo, tanto os planos quanto "a materialização desses nas experiências e relações vividas por professores e alunos no processo de ensinar e aprender conhecimentos" (Moreira, 2001, p. 68). Assim, o professor está inexoravelmente envolvido no planejamento e desenvolvimento do currículo. As políticas neoliberais interferem também na forma como esse currículo é desenvolvido em sala de aula. Essas políticas tendem a diminuir o trabalho intelectual do professor na construção do currículo e no planejamento das atividades pedagógicas; os professores tendem a ser executores "de currículo e metodologia que foram concebidos em outro local e por outros atores" (Gandin \& Lima, 2015, p. 667). 
g) As políticas públicas educacionais no contexto neoliberal ancoramse num rigoroso sistema de avaliação em larga escala, padronizando currículos e controlando a forma como os professores devem lidar com eles. No contexto brasileiro, seguindo as orientações dos organismos internacionais, multiplicaram-se os processos de avaliação da educação básica. Aplicadas em nível nacional, podemos citar a Avaliação Nacional da Educação Básica (ANEB) e a Avaliação Nacional do Rendimento Escolar (ANRESC), conhecida como Prova Brasil. A Prova Brasil é realizada no ensino fundamental e avalia estudantes de $4^{\circ} \mathrm{e} 9^{\circ}$ anos de escolas públicas. Existe ainda, na educação básica, a Provinha Brasil, que tem como foco avaliativo a alfabetização dos estudantes nos anos iniciais do ensino fundamental. Recebe o nome de Avaliação Nacional da Alfabetização (ANA) e é aplicada anualmente aos alunos do $3^{\circ}$ ano do ensino fundamental de escolas públicas. Já o Exame Nacional do Ensino Médio (ENEM), tem o intuito de avaliar os estudantes que estão concluindo o ensino médio, que recém saíram do ensino médio ou que já o concluíram em anos anteriores. Essas avaliações oficiais pretendem determinar o nível de qualidade da educação brasileira; para auxiliar nessa tarefa, em 2007, foi criado o Índice de Desenvolvimento da Educação Básica (IDEB). Além disso, o Brasil integra o Programa Internacional de Avaliação de Estudantes (PISA). Alguns Estados e municípios têm adotado concomitantemente sistemas próprios de avaliação, mas com a mesma lógica, isto é, "a centralidade nos aspectos econômicos em detrimento dos aspectos políticos e sociais, como deslocamento da educação para a esfera do econômico e dos modelos gerenciais apregoados pelo mercado" (Hypólito, 2010, p. 1344). Essas avaliações fazem parte de um eficiente mecanismo de controle dos professores, repercutindo "nos currículos escolares, bem como transformam paulatinamente a cultura escolar e as relações no interior da escola e desta com a comunidade" (Santos, 2013, p. 109). Esse controle, assim como a intensificação do trabalho docente e a responsabilização, ao ser incorporado pelos docentes, torna-se também um autocontrole. 
Cabe destacar que essas avaliações, que supostamente revelam o desempenho do aluno e o quanto/o que o professor ensinou, não são produzidas no contexto escolar, mas por agências especializadas. Se, num primeiro momento, isso revela uma dissociação entre a avaliação e o processo de ensino e aprendizagem, em pouco tempo, os processos articulam-se pela imposição dos conteúdos e formas de trabalhar e de avaliar presentes nas diferentes avaliações externas que as escolas e os professores acabam assumindo, muitas vezes, com a parceria de instituições privadas (Alves, 2009; Gandin \& Lima, 2015; Hypólito, 2010; Oliveira, 2004, 2007, 2013).

h) As políticas públicas educacionais no contexto neoliberal têm se apropriado de alguns valores dos defensores da educação pública, democrática e de qualidade, adaptando os sentidos à lógica do mercado. Entre eles, podemos citar a luta pela profissionalização docente, central na luta dos sindicatos dos professores e do campo crítico da educação na década de 1980, como forma de combater a proletarização. Além disso, "valores como autonomia, participação, democracia foram assimilados e reinterpretados por diferentes administrações públicas, substantivados em procedimentos normativos que modificaram substancialmente 0 trabalho escolar" (Oliveira, 2004, p. 1140). A profissionalização no contexto neoliberal fica em grande parte reduzida à dimensão da formação e não raras vezes a uma formação precária ou aligeirada, como evidencia a exigência de ter apenas a formação em magistério - nível de ensino médio - para atuar na educação infantil. As condições de trabalho vinculam-se a estratégias de autorresponsabilização (em muitos casos, da própria remuneração), autocontrole e autointensificação e à precarização das relações de trabalho como meio de evitar o comodismo. Tudo isso revela, no fundo, ainda que nunca tenhamos tido a profissionalização do docente, um processo de desprofissionalização (Gandin \& Lima, 2015; Hypólito, 2010; Oliveira, 2004). A autonomia, em vez de ser vista como condição de participar na concepção, organização e finalidade do trabalho, 
passa a ser vista como disposição individual de escolher as melhores estratégias para alcançar as metas propostas por outros. A participação e a democracia ficam associadas às possibilidades de as escolas encontrarem parcerias financeiras e pedagógicas para melhorarem a aprendizagem dos seus alunos.

Esse conjunto de políticas educacionais neoliberais contribui para o processo de proletarização docente. Embora não signifiquem a mesma coisa, a burocratização do trabalho docente, as avaliações externas, a lógica mercadológica, a precarização das relações de trabalho e da remuneração atrelada ao desempenho dos alunos, a (auto)responsabilização pelos resultados, a (auto)intensificação do trabalho docente, a ênfase no (auto)controle, as mudanças provocadas no currículo pela adoção das políticas de gerenciamento, a incorporação neoliberal das lutas históricas dos professores, como a profissionalização, a autonomia, a participação e a democracia, mudando os seus sentidos e colocando-os a serviço do mercado, são todos fenômenos que contribuem para a proletarização docente.

\section{O processo de proletarização}

As discussões sobre a proletarização dos docentes no contexto brasileiro estão relacionadas ao processo de empobrecimento econômico dos professores, sobretudo os da educação básica, que se intensificou no período da ditadura militar no Brasil (1964-1985). Se, no início da profissão docente, eram os segmentos da classe média/alta que buscavam o magistério, com o acesso cada vez maior das classes pobres à educação pública, aumenta a necessidade de mais professores. O Estado, alegando falta de recursos, começa a arrochar os salários dos professores. A partir de então, a maioria dos professores da educação básica, se possui formação superior, foi obtida nas faculdades privadas criadas a partir da Reforma Universitária de 1968, reforma essa que incentivou a ampliação do ensino privado no país. Nesse sentido, pode-se dizer que as condições de trabalho dos professores passam a ser semelhantes às de qualquer outro operário da sociedade capitalista: massificação, dependência de empresas privadas, sofrem os efeitos da diminuição dos gastos públicos em educação, baixos salários, intensificação do trabalho, perda de direitos, organização sindical e greve como estratégia de luta (Alves, 2009; Hypólito, 2010; Oliveira, 2004, 2007, 2013). 
Apesar dessas condições de trabalho, a proletarização total do professor é sempre uma impossibilidade, posto que seu trabalho é eminentemente intelectual. Entretanto, não é possível ignorar que as condições de trabalho acabam dificultando seu trabalho intelectual. Nesse contexto, com a redemocratização do Brasil na década de 1980, ganhou corpo, na discussão do campo acadêmico e da luta sindical, a profissionalização docente como uma forma de impedir sua proletarização. Para evitar a proletarização, vista como perda do controle sobre o processo de trabalho, defendia-se a profissionalização "como condição de preservação e garantia de um estatuto profissional que levasse em conta a auto-regulação, a competência específica, rendimentos, licença para atuação, vantagens e benefícios próprios, independência" (Oliveira, 2004, p. 1133).

Como vimos, com a adoção das políticas educacionais neoliberais, essa luta arrefeceu - em parte, porque os sindicatos ficaram fragilizados; em parte, porque essas políticas se apropriaram do termo profissionalização, alinhando-o ao ideário mercantil. Tardif (2013), referindo-se à situação dos professores na América Latina em função das políticas neoliberais, afirma que "a profissionalização parece combinar hoje com uma proletarização de uma parte dos professores" (p. 569), já que ela tem a ver com concorrência, meritocracia, instabilidade e prestação de contas.

Para Contreras (2002), a proletarização se refere à dificuldade ou impossibilidade de o professor refletir sobre sua prática docente, ou seja, "o trabalhador passa a ser um mero executor de tarefas sobre as quais não decide" (p. 35). Ainda dentro desse processo de proletarização, o professor perde sua qualificação, isto é, perde os "conhecimentos e habilidades para planejar, compreender e agir sobre a produção" (Contreras, 2002, p. 35). Por fim, a proletarização leva o professor a perder "o controle sobre o seu próprio trabalho, ao ficar submetido ao controle e às decisões do capital, perdendo a capacidade de resistência" (Contreras, 2002, p. 35). Assim, se tomarmos como base Contreras (2002), podemos dizer que o processo de proletarização faz com que o professor tenha muita dificuldade de pensar sobre sua ação e de resistir, em grande parte porque tem pouca qualificação e é submetido a um forte controle externo.

Ao afirmarmos que o professor tem muita dificuldade, estamos nos afastando de uma visão fatalista de educação. Reconhecemos que, apesar de 
todo o processo de proletarização, há também práticas que circulam nos espaços educativos que lembram que há "professores que atuam como intelectuais transformadores que combinam a reflexão e prática acadêmica a serviço da educação dos estudantes para que sejam cidadãos reflexivos e ativos" (Giroux, 1997, p. 158). Aliás, o próprio Contreras (2002) destaca que o processo de proletarização nunca é totalmente bem-sucedido, pois "a relativa autonomia da escola e do papel do professor cria espaços não definidos nem totalmente fechados, de difícil controle técnico e burocrático, nos quais cabem ações de resistência à imposição racionalizadora" (p. 39).

Entretanto, como argumentamos anteriormente, o processo de proletarização docente está se intensificando devido à adoção das políticas educacionais neoliberais. Segundo Moraes (2004), embora haja uma grande produção acadêmica que aborda o educador e sua formação, são raros os trabalhos que tratam "da produção do conhecimento, de seus processos sempre cumulativos de sedimentação e acréscimo, de crítica e transformação" (p. 141). Isso mostra que os educadores estão se tornando cada vez mais proletários e são capturados pela lógica da eficiência e de "conhecimentos profissionalizados", em que a crítica é vista como perda de tempo e a ideia de transformação social é tida como ultrapassada, uma vez que a retórica oficial é a de que estamos no último estágio de desenvolvimento da humanidade e o capitalismo é o fim para o qual tendem todos os grupos humanos.

Essa captura está relacionada à construção de alguns "padrões civilizatórios", dentre os quais se podem destacar a sociedade da informação e a sociedade do conhecimento. Postula-se que está havendo uma multiplicação da informação e do conhecimento, uma verdadeira democratização. Será que é isso mesmo que está ocorrendo?

Como afirma Moraes (2004), usando o argumento de Chauí, a concentração, reprodução e acumulação do capital estão diretamente ligadas à informação e ao conhecimento (mais à primeira do que ao segundo devido à lógica do capital financeiro, em que a informação é a chave da acumulação instantânea). Entretanto, há um abismo entre o potencial democrático do conhecimento e da informação e sua real efetivação. Uma sociedade neoliberal, a rigor, não combina com democratização do conhecimento e da informação. Isso seria a sua ruína. Os defensores da tese de que existe uma 
democratização do conhecimento e da informação omitem que, cada vez mais, "o poder econômico e a própria noção de desenvolvimento baseiam-se na posse e controle de informação e, portanto, bloqueiam as forças democráticas que reivindicam o direito de acessá-las, compreendê-las, ou dominar seus códigos" (Moraes, 2004, p. 144).

Da mesma forma que a informação relevante não é democratizada, o conhecimento também não é e corrobora com o processo de proletarização dos professores. Assim como se produziu a ilusão de que os conhecimentos estão disponíveis e podem ser buscados por qualquer um, associa-se essa suposta disponibilidade a uma, também suposta, autonomia do professor em acessar esses conhecimentos.

Outra forma de percebermos que a democratização do conhecimento e da informação é uma falácia e corrobora com o processo de proletarização é que se pode observar facilmente que, ao mesmo tempo em que os discursos oficiais estão assumindo essa retórica, estão reduzindo os gastos em educação, deixando as instituições educativas com menos recursos e os educadores de forma geral sem tempo para a produção do conhecimento. Sem maiores constrangimentos, fala-se em "treinamento" de professores, como se estes não precisassem de uma boa formação para o exercício intelectual, para pensar, para refletir criticamente, não só sobre os processos pedagógicos, mas também sobre as implicações políticas desses processos. A educação segue hoje uma política simplista e superficial que pode ser sintetizada da seguinte forma: "praticar, usar e interagir - uma interação circunscrita a uma relação entre produção e consumo de talhe imediato e superficial" (Moraes, 2004, p. 148). Por isso, entendemos que é urgente conceber estratégias de luta em favor da desproletarização dos professores.

Segundo Moraes (2004), é necessário criticar a concepção de conhecimento que vigora hoje na educação, incluindo a escolar: o conhecimento sanitarizado, ou seja, o conhecimento prático: "a supremacia do saber-fazer desqualifica o esforço teórico à perda de tempo e à especulação metafísica" (Moraes, 2004, p. 149). Ainda segundo a autora, como efeitos dessa retórica do conhecimento prático, temos a "desintelectualização" do professor e sua despolitização, reafirmando a suposta neutralidade da educação, propalada em nome de um saber técnico (considerado útil) em detrimento de um saber político (supostamente inútil, perda de tempo). 
Para lutar contra a proletarização, o entendimento da dimensão política de todo e qualquer conhecimento é fundamental. Numa sociedade em que o conhecimento é uma condição cada vez mais importante na definição das fronteiras da inclusão/exclusão, não só se deve enfatizar o conhecimento nos processos educativos, mas lutar para que ele seja gratuito e público para toda a vida. Mas não se trata de qualquer conhecimento. Aqui a velha - mas nem por isso menos atual - afirmação de que não há neutralidade no conhecimento é de suma importância.

$\mathrm{Na}$ dimensão de um conhecimento que signifique uma ruptura com o processo de proletarização do professor, o conhecimento, mais do que servir para adaptar-se às exigências do mercado, deve ser uma ferramenta para compreender os processos de exclusão e controle e desenvolver experiências alternativas. Estas devem ser experiências coletivas, pois a luta de indivíduos é sempre uma luta suicida. Só por meio da organização coletiva as possibilidades de transformação social começam a surgir.

Como se situam os professores dentro desse contexto de proletarização é o que vamos abordar no próximo item, lembrando que postulamos que, apesar de toda a imposição da proletarização, há possibilidades de romper com esse processo.

\section{O processo de captura do professor da educação básica}

Nóvoa (2002) nos chama atenção para o mal-estar docente que tem se acentuado desde os anos de 1980. O autor, de modo semelhante a Contreras (2002), leva-nos a pensar sobre o processo de proletarização. Segundo ele, a profissão docente encontra-se submetida a duas tensões: "a tendência para separar a concepção da execução, isto é, a elaboração dos currículos e dos programas da sua concretização pedagógica" (Nóvoa, 2002, p. 55) e a intensificação do trabalho docente, ou seja, "uma inflação de tarefas diárias e uma sobrecarga permanente de actividades" (Nóvoa, 2002, p. 55). Podemos recorrer ainda a Hargreaves (1998) quando escreve: "Para o docente, o tempo não só constitui uma restrição objetiva e opressora, senão também um horizonte de possibilidades e limitações subjetivamente definido" (p. 119).

Para explicitar de que forma os docentes são capturados e se encontram num processo de proletarização que se intensificou com as 
políticas educacionais neoliberais, apresentamos algumas falas dos professores entrevistados que denotam tal processo.

A professora Liana, professora do $1^{\circ}$ ano do Ensino Fundamental da Rede Pública de Ensino, embora afirme que as professoras "são livres para ver as necessidades da sala de aula", ao se referir ao conteúdo curricular trabalhado no ano letivo, pontua: "Este ano foi muito bom, nós conseguimos seguir certinho o que foi passado da Secretaria de Educação para nós".

A fala da professora Liana lembra-nos de Arroyo (2000). O autor traz uma reflexão acerca das práticas educacionais que colocam o professor como alguém tutelado: "Essa prática tem raízes na visão que se tem e mantém de professor tutelado, por normas ou por orientações e supervisões, por minorias multiplicadoras de pães e peixes pedagógicos, para a faminta multidão de professores que os segue" (p. 221). Porém, quando a professora menciona o "espaço livre da sala de aula", lembra Contreras (2002), citado anteriormente, que afirma a impossibilidade absoluta da proletarização e aponta o espaço da sala de aula como um espaço de difícil controle burocrático.

De modo semelhante ao da professora Liana, a professora Anelise, professora do $4^{\circ}$ ano do Ensino Fundamental da Rede Pública de Ensino, aponta que tem liberdade para alterar a seleção dos conteúdos conforme a realidade se apresenta. No entanto, quando questionada sobre que critérios utiliza para selecionar os conteúdos, afirma: "Como eu te falei, a gente segue as diretrizes (...)".

Já a professora Renata, professora do $3^{\circ}$ ano do Ensino Fundamental da Rede Pública de Ensino, quando questionada sobre como seleciona o seu conteúdo curricular, apresenta um material produzido pela Secretaria de Educação e afirma: "Nós temos um conteúdo para ser executado, não sei se você já viu (...)". Baseados em Alves (2009), pode-se dizer que a professora vive a intensificação da proletarização, pois o "trabalho docente vem a cada dia expressando menos autonomia, maior divisão, intensificação e fragmentação" (p. 35).

No contexto atual, há uma "proliferação do que tem se chamado pacotes curriculares 'à prova de professores'" (Giroux, 1997, p. 160). Esses pacotes curriculares pretendem reduzir o trabalho do professor à mera execução: "A fundamentação subjacente de muitos destes pacotes reserva 
aos professores o simples papel de executar procedimentos de conteúdos e instrução predeterminados" (Giroux, 1997, p. 160). Ao pretenderem transformar os professores em executores, esses pacotes corroboram com a proletarização docente.

Por fim, a professora Ester, professora do $5^{\circ}$ ano do Ensino Fundamental da Rede Privada de Ensino, questionada sobre o currículo escolar, responde que: "Currículo escolar é este conjunto de atividades, determinadas pelos PCNs (...]".

Como se pôde observar, todas as cinco ${ }^{1}$ professoras entrevistadas da escola pública dos anos iniciais do Ensino Fundamental citaram os órgãos e documentos oficiais como norteadores da sua ação. Citamos ainda algumas das várias falas de professoras que mostram como, no atual contexto, as políticas neoliberais de educação interferem diretamente no trabalho pedagógico do professor, levando-o a ensinar:

(...) o que realmente é cobrado de conteúdo, como é cobrado e de que forma, para estar passando para os alunos. Porque, às vezes, você está seguindo uma linha e eles estão cobrando outra. (...) A gente trabalha em cima desses dados (Professora de Matemática do $6^{\circ}$ ao $9^{\circ}$ anos do ensino fundamental)

A gente explicou para os alunos como eles seriam avaliados. Então, quando eles fizeram a prova, eles foram bem preparados, assim, psicologicamente, sabendo o que seria avaliado. Nós adaptamos as aulas conforme as avaliações. (Professora de Língua Portuguesa do $6^{\circ}$ ao $9^{\circ}$ anos do ensino fundamental)

As falas das sete professoras lembram em muito Alves (2009), Contreras (2002), Gandin e Lima (2015), Giroux (1997), Grischke e Hypólito (2009), Hypólito (2010), Oliveira (2004, 2007, 2013), Santos (2013) e Santos et al. (2013), quando desenvolvem reflexões que contribuem para compreender o processo de proletarização dos professores no contexto atual, intensificado com a adoção das políticas educacionais neoliberais.

Além dessas professoras, foram entrevistados professores do Ensino Médio da rede pública ${ }^{2}$, e quase todas as respostas vêm ao encontro das falas das professoras do Ensino Fundamental.

A professora Elia, quando caracteriza o currículo escolar, embora aponte que ele é flexível, afirma: 
Vem predeterminado o que temos que trabalhar. Eu considero bom, né? Logicamente que o professor não tem que seguir exatamente a forma que vem, ele tem que primeiramente diagnosticar a realidade com que ele vai trabalhar. (Professora de Artes do $1^{\circ}$ ao $3^{\circ}$ anos do Ensino Médio da Rede Pública de Ensino)

Cabe registrar que, em nenhum momento da entrevista, observamos alguma reflexão no sentido de questionar ou refletir sobre quem predetermina esse conteúdo. Novamente Giroux (1999) nos ajuda a entender o posicionamento da professora. De acordo com o autor, "nós instrumentalizamos tanto o processo da educação que esquecemos que a referência a partir da qual operamos é uma lógica da classe média alta, branca, que não só modula, mas na verdade silencia as vozes subordinadas" (Giroux, 1999, p. 25).

A professora Leandra, professora de Educação Física do $1^{\circ}$ ao $3^{\circ}$ anos do Ensino Médio da Rede Pública de Ensino, ao ser questionada sobre como seleciona os conteúdos curriculares, responde: "É, bem, o referencial do Estado. Aí, no começo do ano, a gente vê o que o referencial fala e a gente monta a partir desse referencial, monta na integridade (...)".

Essa separação entre a definição e execução do trabalho pedagógico explicitada pelas professoras produz a "certeza" de que

(...) o ensino é um problema técnico e que, por conseguinte, requer um conhecimento aplicado para poder resolver os problemas das aulas e dos alunos, reforça a ideia de que um bom profissional do ensino será aquele que dominar um amplo repertório técnico. (Contreras, 2002, p. 50)

Como apontam os autores críticos, a educação nunca é apenas um problema técnico, ela sempre tem uma dimensão política e social, e precisa estar articulada com a construção da justiça social. A ênfase na técnica em detrimento das outras dimensões acaba contribuindo para a proletarização docente, pois o docente é levado a refletir apenas sobre o "efeito sala de aula" (Oliveira, 2013, p. 58).

O professor Carlos, quando perguntado sobre como elabora seu plano de ensino e como seleciona os conteúdos, expressa:

(...) nós usamos o Referencial Curricular, e não pode fugir daquilo. Nosso planejamento anual, principalmente agora, ele tem que ser em cima do Referencial Curricular que foi elaborado pelo Governo do Estado com a participação, inclusive, dos professores. (Professor de História do $1^{\circ}$ ao $3^{\circ}$ anos do Ensino Médio da Rede Pública de Ensino) 
Se considerarmos o que nos aponta Ponce (1997), isto é, que o tempo de contrato de trabalho geralmente é apenas "o tempo do seu trabalho com o aluno, em sala de aula, o que reforça a concepção do professor-executor, aquele que não precisa dispor de tempo para construir projetos e se construir, já que apenas executa e para isso é contratado e assalariado" (p.87), chegamos à conclusão de que a participação citada pelo professor foi muito incipiente.

Mas queremos lembrar o que escrevemos no início deste texto: que não pretendemos fazer uma leitura fatalista do processo de proletarização como se este fosse absoluto e irreversível. Queremos, fazendo novamente referência a Contreras (2002), lembrar que a escola e a atividade docente são de difícil controle burocrático. Por isso, entendemos que, apesar de os professores entrevistados terem apontado os órgãos oficiais ou os documentos oficiais como conteúdos que foram previamente planejados e que devem ser seguidos, há inúmeros microespaços de resistência e subversão, alguns deles percebidos na nossa pesquisa e talvez muitos outros que escaparam ao nosso olhar. Como microespaços percebidos por nossa pesquisa, queremos lembrar a fala da professora Liana, que afirmou que tem liberdade para olhar as necessidades da sala de aula; a da professora Anelise, que afirmou que tem liberdade de alterar a ordem dos conteúdos, de acordo com a realidade; a da professora Elia, que observou a flexibilidade no currículo escolar; a do professor Carlos, que mencionou a participação dos professores na elaboração dos conteúdos.

Embora não se possa afirmar que esses microespaços citados (e tantos outros não percebidos) indiquem que não há um processo de proletarização, pode-se afirmar que eles indicam, pelo menos, que esse processo em curso não é irreversível, tampouco total e absoluto. Assim como Giroux (1997), fazemos um esforço para, apesar de muitas vezes se observar o contrário, identificar espaços de luta e transformação social ou acreditar na mudança, não por uma questão de teimosia, mas por uma necessidade ontológica, pois, sem acreditarmos na mudança, tornamo-nos desanimados e sentimo-nos até mesmo incapazes de lutar.

Entendemos, ainda, juntamente com os autores citados neste texto, que a desproletarização passa pela formação crítica do professor, uma formação que seja capaz de questionar as políticas educacionais neoliberais, 
sobretudo seus efeitos perversos para as condições de trabalho dos docentes e sua opção por privilegiar o mercado que transforma a educação em mercadoria, ao invés de um instrumento de construção da justiça social.

\section{A formação crítica como possibilidade de ruptura com a proletarização}

O contexto educacional marcado pelas políticas neoliberais dificulta 0 processo de reflexão crítica dos professores. Como argumentamos, vários termos que foram utilizados na luta por melhores condições de trabalho para os professores foram apropriados e adaptados ao ideário neoliberal. Com o conceito de reflexão, ocorreu algo semelhante. Segundo Zeichner (2008), ele se tornou um slogan na educação, utilizado por diferentes tendências políticas e ideológicas.

As políticas educacionais neoliberais, de forma sutil, levam os professores a refletir sem questionar a sua subserviência. Nessa lógica, eles são incentivados a refletir sobre seus fracassos individuais sem pensar sobre as estruturas e condições de trabalho em que atuam, que efetivamente são a causa dos problemas da educação. A reflexão facilmente se torna "uma ferramenta para se controlar mais tacitamente os professores" (Zeichner, 2008, p. 547).

Por isso a defesa da reflexão crítica dos professores continua fundamental. Além de levar sempre em conta o contexto, as condições de trabalho e as formas de controle e de opor-se radicalmente às políticas educacionais neoliberais, a reflexão crítica sempre tem uma preocupação em fazer da educação um instrumento de justiça social (Alves, 2009; Gandin \& Lima, 2015; Grischke \& Hypólito, 2009; Hypólito, 2010; Oliveira, 2004, 2007, 2013; Santos, 2013; Santos et al., 2013; Zeichner, 2008).

Entendemos, juntamente com os autores que utilizamos neste texto, que uma das formas de potencializar a resistência do professor contra 0 processo de proletarização passa por uma formação crítica que veja a racionalidade técnica como limitada e insuficiente, pois a realidade social é demasiado rica para se encaixar em esquemas preestabelecidos. "A tecnologia educativa não pode continuar a lutar contra as características, cada vez mais evidentes, dos fenômenos práticos: complexidade, incerteza, instabilidade, singularidade e conflito de valores" (Gómez, 1997, p. 99). 
Para poder considerar as características da educação, é fundamental que os professores tenham uma formação em que a reflexão crítica seja o eixo articulador. Estamos usando a reflexão crítica por entendermos, junto com Pimenta (2005), que o ato de refletir é uma característica ontológica dos seres humanos. Porém, existem diferentes tipos de reflexão. É possível, por exemplo, fazer uma reflexão que esteja restrita ao espaço da sala de aula, ou apenas sobre a relação professor e aluno, ou sobre a melhor técnica a ser empregada, e assim por diante. Apesar de estas serem consideradas por muitos autores como práticas reflexivas, entendemos, assim como os autores críticos, que elas se situam no nível instrumental/técnico e não levam ao questionamento das dimensões políticas, econômicas, sociais e culturais dos processos educativos.

É nesse sentido que recorremos à formação e à reflexão crítica como a que dá conta da complexidade do ato educativo. Para os autores críticos, a educação está irremediavelmente ligada ao contexto social, político, econômico, cultural e a luta pela justiça social. Como tal, não pode ser compreendida, tampouco o papel do educador, nem o processo de proletarização e suas possibilidades de ruptura, se essas dimensões não forem contempladas durante a formação inicial e continuada do professor. Lembramos que "o profissional competente possui capacidades de autodesenvolvimento reflexivo" (Nóvoa, 1997, p. 27).

Portanto, é necessário que o professor reflita criticamente para compreender a educação, seu papel e o processo de proletarização, lembrando que a "lógica da racionalidade técnica opõe-se sempre ao desenvolvimento de uma práxis reflexiva" (Nóvoa, 1997, p. 27).

Pensamos que a formação e reflexão crítica são fundamentais também no contexto atual para não cairmos na armadilha de responsabilizar os professores pelos problemas da educação, como sugerem as atuais políticas educacionais. No caso específico dos professores que se dispuseram a participar de nossa pesquisa, ressaltamos seu próprio trabalho e as incessantes medidas de proletarização a que estão submetidos.

Consideramos relevante destacar (novamente) que os próprios profissionais da educação, ao longo de suas vidas, sentiram/sentem os efeitos da proletarização, sobretudo por terem sido excluídos de um tempo adequado para a reflexão (crítica) e submetidos a condições precárias de 
trabalho. Como vimos, com a adoção das políticas educacionais neoliberais, as condições pioraram ainda mais. Como aponta Tardif (2002), é preciso considerar que os professores foram produzidos em um ambiente em que historicamente se tentou reduzir a atuação docente à execução das aulas, sem ter, no próprio ambiente escolar, discussão, debate, enfim, espaço/tempo para a reflexão sobre o processo educativo, quiçá sobre o processo da sociedade, ainda que, como sabemos pela teoria crítica, estes não se deem de forma separada.

Nesse sentido, fazemos nossas as palavras de Althusser (2001): pedimos "desculpas aos professores que, em condições assustadoras, tentam voltar contra a ideologia, contra o sistema e contra as práticas que os aprisionam, as poucas armas que podem encontrar na história e no saber que 'ensinam"' (p. 81). O fato de citarmos Althusser (2001) não quer dizer que nos filiamos ao pensamento do autor na íntegra, pois, como já destacamos anteriormente, entendemos que há espaços e práticas de resistência nas diferentes escolas. Apesar do processo de proletarização, há possibilidades de ruptura, algumas já em curso, outras ainda por ser construídas. Portanto, "estamos mais interessados em atrelar esta linguagem de análise crítica a uma linguagem de possibilidade a fim de desenvolver práticas alternativas de ensino que sejam capazes de destruir a lógica de dominação dentro e fora das escolas" (Giroux, 1997, p. 203).

Para que haja essa articulação entre a análise crítica e a linguagem da possibilidade, capaz de romper com o processo de proletarização, entendemos que a formação inicial e continuada deve contemplar a dimensão crítica.

\section{Considerações finais}

Como destacamos ao longo do texto, nossa intenção foi refletir sobre os processos de proletarização em curso na educação. De forma alguma foi nossa intenção responsabilizar/culpabilizar os professores de forma geral, tampouco os que por livre e espontânea vontade se dispuseram a participar de nossa pesquisa. A reflexão crítica nos faz sempre privilegiar, na análise, as relações dos sujeitos com o seu entorno, não os vendo simplesmente como indivíduos que agem segundo sua vontade individual. 
Portanto, para romper com o processo de proletarização, é fundamental lutar contra os processos de injustiça que estão presentes na sociedade. É fundamental, ainda, superar o modelo econômico vigente e suas políticas educacionais neoliberais responsáveis pelo aumento da proletarização dos professores.

Por fim, reiteramos nossa postura antifatalista, porque apostamos na capacidade dos seres humanos de construir novas relações sociais, novas relações de produção, novas formas de educar - isto é, novamente unimos a linguagem da crítica com a linguagem da possibilidade. Nessa dimensão, "a esperança torna-se antecipatória em vez de compensatória" (Giroux, 2003, p. 44).

\section{Notas}

1 Esclarecemos que a pesquisa contemplou mais professores do que os que foram citados neste texto, mas as respostas revelam posturas semelhantes.

2 Também do Ensino Médio foram entrevistados mais professores, mas, para fins deste texto, citamos três.

\section{Referências}

Althusser, L. (2001). Aparelhos ideológicos de Estado: Nota sobre os aparelhos ideológicos de Estado. Rio de Janeiro: Graal.

Alves, A. E. S. (2009). Trabalho docente e proletarização. Revista HISTEDBR, 36, 2537.

Arroyo, M. G. (2000). Ofício de mestre: Imagens e auto-imagens. Petrópolis, RJ: Vozes.

Contreras, J. (2002). A autonomia de professores. São Paulo: Cortez.

Gandin, A., \& Lima, I. G. (2015). Reconfiguração do trabalho docente: Um exame a partir da introdução de programas de intervenção pedagógica. Revista Brasileira de Educação, 20(62), 663-677.

Giroux, H. A. (1997). Os professores como intelectuais: Rumo a uma pedagogia crítica da aprendizagem. Porto Alegre: Artes Médicas.

Giroux, H. A. (1999). Cruzando as fronteiras do discurso educacional: Novas políticas em educação. Porto Alegre: Artmed.

Giroux, H. A. (2003). Atos impuros: A prática política dos estudos culturais. Porto Alegre: Porto Alegre: Artmed. 
Gómez, A. P. (1997). O pensamento prático do professor: A formação do professor como profissional reflexivo. In A. Nóvoa (Org.), Os professores e a sua formação (pp. 95-114). Lisboa: Dom Quixote.

Grischke, P. E., \& Hypólito, A. M. (2009). Entre a gestão burocrática e o novo gerencialismo: A organização do trabalho docente na educação profissional. Trabalho e Educação, 18(1), 107-120.

Hargreaves, A. (1998). Profesorado, cultura e postmodernidad: Cambian los tiempos, cambia el profesorado. Madrid: Morata.

Hypólito, A. M. (2010). Políticas curriculares, Estado e regulação. Educação \& Sociedade, 31(113), 1337-1354.

Moraes, M. C. M. (2004). Incertezas nas práticas de formação e no conhecimento docente. In A. F. B. Moreira, J. A Pacheco, \& R. L. Garcia (Org.), Currículo: Pensar, sentir e diferir (pp. 139-158). Rio de Janeiro: DP\&A.

Moreira, A. F. B. (2001). A recente produção científica sobre currículo e multiculturalismo no Brasil (1995-2000): Avanços, desafios e tensões. Revista Brasileira de Educação, 18, 65-81.

Nóvoa, A. (1997). Formação de professores e profissão docente. In A. Nóvoa (Org.), Os professores e a sua formação (pp. 14-33). Lisboa: Dom Quixote.

Nóvoa, A. (2002). Formação de professores e trabalho pedagógico. Lisboa: Educa.

Oliveira, D. A. (2004). A reestruturação do trabalho docente: Precarização e flexibilização. Educação \& Sociedade, 25(89), 1127-1144.

Oliveira, D. A. (2007). Política educacional e a re-estruturação do trabalho docente: Reflexões sobre o contexto latino-americano. Educação \& Sociedade, 28(99), 355-375.

Oliveira, D. A. (2013). As políticas de formação e a crise da profissionalização docente: Por onde passa a valorização? Revista Brasileira de Educação, 46(32), 51-74.

Pimenta, S. G. (2005). Professor reflexivo: Construindo uma crítica. In S. G. Pimenta \& E. Ghedin (Orgs.), Professor reflexivo no Brasil: Gênese e crítica de um conceito (pp. 17-52). São Paulo: Cortez.

Ponce, B. J. (1997). O professor como sujeito da ação social ou da urgente e necessária revitalização da profissão docente. Revista de Educação AEC, 104, 85-118.

Santos, A. V., Guimarães-losif, R. M., \& Chaves, V. L. J. (2013). Formação dos oligopólios na educação superior privada brasileira: Sobreimplicação no trabalho docente. Educação em Questão, 46(32), 75-97.

Santos, L. L. C. P. (2013). As duas faces da avaliação. In A. M. P. Favacho, J. A. Pacheco, \& S. R. Sales (Orgs.), Currículo: Conhecimento e avaliação, divergências e tensões (pp. 109-122). Curitiba: CRV.

Tardif, M. (2002). Saberes docentes e formação profissional. Petrópolis, RJ: Vozes.

Tardif, M. (2013). A profissionalização do ensino passados trinta anos: Dois passos para a frente, três para trás. Educação \& Sociedade, 34(123), 551-571.

Zeichner, K. M. (2008). Uma análise crítica sobre a "reflexão" como conceito estruturante na formação docente. Educação \& Sociedade, 29(103), 535-554. 


\title{
THE PROCESS OF DE-PROLETARIANIZATION OF BASIC EDUCATION TEACHERS
}

\begin{abstract}
Proletarianization is characterized by either the difficulty or impossibility teachers have to reflect about their teaching practice. It is also characterized by the loss of both their qualification (to plan, analyze, act and evaluate) and their control over their work process, and this makes them hostages to external control and gradually decreases their autonomy and resistance capacity. The aim of this paper is to reflect on the proletarianization of Basic Education teachers, regarding how this process takes place and possibilities to disrupt it. The empirical study was carried out with primary and secondary teachers of the central and western part of Brazil, by means of an interview. We have concluded that one of the ways to potentialize teachers' resistance against the proletarianization process implies a critical kind of education that regards the technical rationality as limited and insufficient, since social reality is rather rich to fit pre-established frames.
\end{abstract}

Keywords

Teacher education; Proletarianization; Critical reflection

\section{EL PROCESO DE (DES)PROLETARIZACIÓN DEL PROFESOR EN LA EDUCACIÓN BÁSICA}

\section{Resumen}

La proletarización se caracteriza por la dificultad o imposibilidad del profesor reflexionar sobre su práctica docente. Caracterizado además por la perdida de la cualificación (para planear, analizar, actuar y evaluar) y del control sobre su proceso de trabajo, lo que lo hacen rehén del control externo, disminuyendo progresivamente su capacidad de autonomía y resistencia. El objetivo de este artículo es reflexionar sobre la proletarización del profesor de educación básica en el contexto actual, como ocurre este proceso y las posibilidades de 
romperlo. La investigación de campo fue realizada por medio de entrevistas con profesores de la Educación Básica ubicadas en la región centro oeste del Brasil. Por la investigación realizada concluimos que los profesores entrevistados están sometidos al proceso de proletarización, aunque este no sea total y absoluto, pues fue posible identificar micro espacios de resistencia.

Palabras clave

Formación de profesores; Proletarización; Reflexión crítica

Recebido em agosto/2015 Aceite para publicação em fevereiro/2016

i Programa de Pós-Graduação em Educação, Universidade Católica Dom Bosco, Brasil.

ii Programa de Pós-Graduação em Educação, Universidade Católica Dom Bosco, Brasil.

Toda a correspondência relativa a este artigo deve ser enviada para: Ruth Pavan, Rua das Paineiras, n. 1000, ap. 32, Bairro Gomes, Campo Grande - Mato Grosso do Sul - Brasil, CEP: 79022-110. E-mail: ruth@ucdb.br 